\title{
Mudanças no uso e cobertura da terra do entorno da Lagoa de Ibiraquera (Santa Catarina, Brasil) no período de 1957 a 2011
}

Rodrigo Rodrigues de Freitas* Ângela da Veiga Beltrame**

\section{Resumo}

A compreensão das forças direcionadoras das mudanças no uso e cobertura da terra requer o uso de diferentes métodos de pesquisa e um enfoque interdisciplinar. As mudanças ocorridas nos últimos 130 anos na paisagem do entorno da Lagoa de Ibiraquera (Santa Catarina, Brasil) são analisadas em duas fases: (i) de 1880 até o final da década de 1970 e (ii) desde o início dos anos 1980 até 2011. Foram classificadas as seguintes classes de uso e cobertura da terra: Floresta Ombrófila, Restinga, Reflorestamento, Capoeirinha, Agricultura, Campo e Urbanização. No final da primeira fase, cerca de $48 \%$ da vegetação nativa havia sido convertida em Agricultura (26,4\%) e Campo (22\%). Na década de 1970, a rede viária possibilitou a integração da paisagem ao mercado nacional, gerando aumento do turismo e das áreas urbanizadas. Os resultados desta pesquisa são analisados por meio de teorias sobre mudanças na paisagem e oferecem subsídios ao planejamento de políticas integradas de desenvolvimento e conservação nas zonas costeiras.

Palavras-chave: Zona Costeira; Mudança na paisagem; Uso da terra; Floresta Atlântica.

Doutorando do Programa de Pós-Graduação em Ambiente e Sociedade da Universidade Estadual de Campinas/UNICAMP. Núcleo de Estudos e Pesquisas Ambientais (NEPAM) (rodrigo.manejo@gmail.com).

** Programa de Pós-Graduação em Geografia, Departamento de Geociências CFH/UFSC (beltrame@cfh.ufsc.br).

Geosul, Florianópolis, v. 27, n. 54, p 77-98, jul./dez. 2012 
DE FREITAS, R.R. \& BELTRAME, A.V. Mudanças no uso e cobertura...

Change in land use and cover in Ibiraquera Lagoon surrounding (Santa Catarina, Brasil) in the period of 1957 to 2011

\section{Abstract}

Understand the driving forces in land change and land cover requires the use of different research methods and an interdisciplinary approach. Changes occurred in the last 130 years in Ibiraquera Lagoon Landscape (Santa Catarina, Brasil) are analyzed in two phases: (i) 1880 until the end of 1970's and (ii) since the beginning of the 80's until 2011. It was classified the following classes of land cover and use: Floresta Ombrófila, Restinga, Reflorestamento, Capoeirinha, Agricultura, Campo e Urbanização. In the end of the first phase, around $48 \%$ of native vegetation have been converted in Agriculture (26,4\%) and Field $(22 \%)$. In the 1970's, the road network allowed the landscape integration in national market, generation increase in tourism and urban areas. The results of this research are analyzed through theories about landscape change and offer subsidies for planning development and conservations integrated policies in coastal zones. Key words:

\section{Introdução}

As paisagens costeiras vêm sendo alteradas em um ritmo acelerado nos últimos 40 anos em todo o mundo (SHI E SINGH, 2003). O entendimento das principais forças direcionadoras das mudanças em paisagens requer um enfoque histórico, que busque explicações em condicionantes presentes nas escalas espaciais mais amplas e que correlacione os atributos físicos e biológicos, com aspectos culturais, políticos e econômicos. Trata-se, em síntese, de uma tarefa complexa e interdisciplinar, que tende a focar nas especificidades do local para não correr o risco de errar nas generalizações.

Apesar da necessidade de levar em consideração as especificidades, recentemente alguns trabalhos vem tentando 
DE FREITAS, R.R. \& BELTRAME, A.V. Mudanças no uso e cobertura...

construir hipóteses sobre as mudanças na paisagem que conduzam a uma teoria explicativa (DOMON e BOUCHARD 2007; BÜRGI et al., 2010). O objetivo deste artigo é discutir padrões presentes nas mudanças ocorridas na paisagem do entorno da Lagoa de Ibiraquera (Santa Catarina, Brasil), nos últimos 130 anos, visando contribuir com perspectivas integradas de desenvolvimento e conservação da natureza no nível regional. O entorno da Lagoa de Ibiraquera foi ocupado inicialmente por descendentes de açorianos, cujo modo de produção é caracterizado pelo minifúndio, policultura de subsistência, pesca e extrativismo animal e vegetal. A comercialização era realizada com o excedente da produção e com a farinha de mandioca. Estas atividades permitiram a sobrevivência desta população desde 1880 até a década de 1970 do século passado. Porém, os custos ambientais destas atividades revelarem-se elevados, pois até 1957, a maior parte da cobertura vegetal nativa já havia desaparecido.

A paisagem do entorno da Lagoa de Ibiraquera objeto deste estudo, localiza-se entre as coordenadas $28^{\circ} 05^{\prime} 05^{\prime \prime}$ e $28^{\circ} 11^{\prime} 42^{\prime \prime}$ ' de latitude sul e 48 $37^{\circ} 24^{\prime \prime}$ ' e $48^{\circ} 42^{\prime} 06^{\prime}$ ' de longitude oeste, no Estado de Santa Catarina, sul do Brasil. Constituem a área estudada: parte da Bacia Hidrográfica da Lagoa de Ibiraquera e as Bacias Hidrográficas da Praia do Rosa, da Praia Vermelha e da Praia do Ouvidor. Limita-se ao norte com a Rodovia SC 434, a oeste com a Rodovia BR-101, a leste com a linha da costa junto ao Oceano Atlântico e ao sul com o divisor de águas que margeia a Lagoa Doce. A dimensão total da área de estudo são $46,23 \mathrm{Km}^{2}$, contudo, sem considerar a extensão da Lagoa de Ibiraquera, sobram 37,27 $\mathrm{Km}^{2}$ (Figura 01), que englobam as seguintes comunidades: Campo D'una, Grama e Limpa, pertencentes ao município de Garopaba, e Araçatuba, Ibiraquera ou Teixeira, Alto Arroio, Arroio, Rosa e Barra, pertencentes ao município de Imbituba.

\section{Metodologia}


DE FREITAS, R.R. \& BELTRAME, A.V. Mudanças no uso e cobertura...

A pesquisa utilizou como metodologia consulta a fontes documentais, entrevistas utilizando história oral (THOMPSON, 1992) e interpretação de fotografias aéreas e imagens de satélite. Entre janeiro e julho de 2004 foram entrevistados 27 moradores tradicionais idosos com uso de um de gravador e roteiro semiestruturado. O roteiro de entrevista abordou a história de vida do entrevistado, questões relativas ao mundo do trabalho (lavoura e pesca), economia, cultura local e percepções sobre as mudanças na paisagem. A escolha dos entrevistados foi realizada tendo em vista os seguintes critérios: (i) possuir cerca de 70 anos; (ii) ter condições psicológicas de memorar; (iii) residir no local desde a infância até a terceira idade; (iv) representação espacial das oito comunidades.
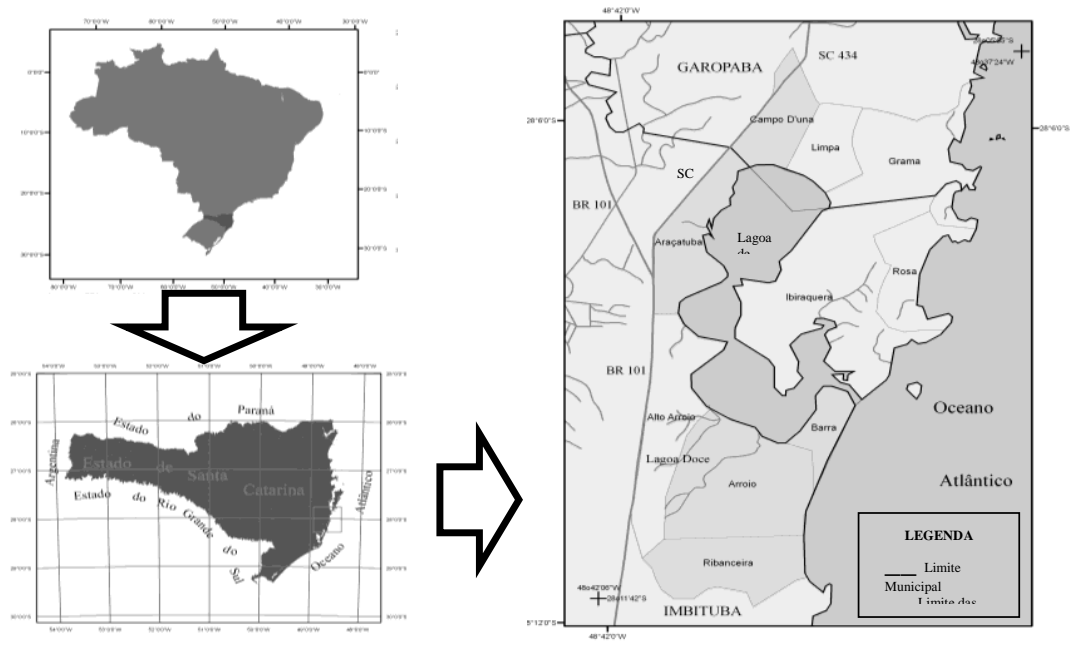

FIGURA 1: Mapa de localização das comunidades no entorno da Lagoa de Ibiraquera, municípios de Imbituba e Garopaba, Santa Catarina (Brasil). 
DE FREITAS, R.R. \& BELTRAME, A.V. Mudanças no uso e cobertura...

O material cartográfico reunido para interpretação constou de levantamentos aerofotogramétricos dos anos de 1957 (1:25.000), 1978 (1:25.000) e 2001 (1:20.000). A fotointerpretação analógica dos overlays foi realizada em papel vegetal com o uso de estereoscópio ótico (Eng Level). Na digitalização, o papel vegetal contendo as categorias foi escaneado em 600 DPI's e georreferenciado sobre a mosaicagem ${ }^{1}$ dos overlays, havendo um erro médio de $8,3 \mathrm{~m}$ no georreferenciamento. Na vetorização, cada polígono foi convertido para o formato vetorial, por meio do programa SIG Arc View 8.3 da ESRI e seus aplicativos. Na limpeza topológica os polígonos menores ou iguais a $500 \mathrm{~m}^{2}$ foram unificados ao maior polígono adjacente. Finalizados os mapas, os erros foram corrigidos através da padronização por meio de comparação entre as categorias presentes nos anos de 1957, 1978 e 2001.

O mapa de uso e cobertura da terra do ano de 2008 foi gerado a partir de uma imagem pancromática do satélite CBERS 2B (sensor HRC) tirada em julho, com uma resolução espacial de 260 x $260 \mathrm{~m}$ na escala de 1:55.000. Para elaboração do mapa de 2008 foi utilizando como referência o mapa de uso e cobertura da terra de 2001.

As classes de uso e cobertura da terra foram produzidas através de pesquisa bibliográfica e levantamento de campo. A vegetação nativa foi classificada segundo as fitofisionomias da Floresta Atlântica de Santa Catarina proposta por Klein (1984 e 1990) e Reitz (1961). A bibliografia consultada elegeu classes fitofisionômicas preliminares, as quais foram verificadas em campo durante 2004 com o auxilio das fotos aéreas de 2001 e de especialistas (M.M. Gomes). De acordo com a resposta espectral, as imagens foram classificadas, polígono a polígono, nas seguintes classes: Capoeirinha, Floresta Ombrófila Densa Submontana e de Terras Baixas, Vegetação de Restinga Arbórea, Herbácea e

${ }^{1}$ União de duas ou mais fotografias aéreas com o intuito de possibilitar sua visualização integral sem as "quebras". 
DE FREITAS, R.R. \& BELTRAME, A.V. Mudanças no uso e cobertura...

Arbustiva, Banhado, Reflorestamento, Agricultura, Campo e Urbanização. Para facilitar a visualização nos mapas de uso e cobertura da terra, as Florestas Ombrófilas Densas e as Vegetações de Restinga foram agrupadas e o Banhado unificado às Lagoas.

As formações vegetais nativas assumem diferentes fitofisionomias dependendo da forma do relevo que colonizam, sua estrutura e composição florística. A Floresta Ombrófila Densa de Terras Baixas, por exemplo, está situada nas depressões abaixo de $30 \mathrm{~m}$ e a Vegetação de Restinga Arbórea acima de $30 \mathrm{~m}$. A Capoeirinha é uma etapa da coivara, que consiste na queima dos restos vegetais visando novos cultivos. Corresponde as áreas onde atividades agrícolas foram recentemente abandonadas (5 a 10 anos) havendo predomínio da vassoura-vermelha (Dodonea sp.) e da vassoura-branca (Baccharis sp.).

O Reflorestamento corresponde aos locais com espécies arbóreas exóticas de crescimento rápido, sendo as espécies mais utilizadas o Eucaliptus sp., a Casuarina sp. e Pinus spp.. Eucaliptus sp se encontra distribuído em manchas, normalmente próximas às residências e as demais espécies exóticas se situam próximos à Vegetação de Restinga. Áreas com Vegetação de Restinga em Dunas Fixas e Semi-Fixas são os ambientes mais suscetíveis à invasão do Pinus (BECHARA, 2003 e ZILLER, 2000). As áreas de reflorestamento com exóticas impossibilitam a regeneração de espécies nativas pela baixa presença da fauna nativa dispersora de sementes (CARUSO, 1983). Por serem heliófitas, essas exóticas não oferecem condições para as pioneiras nativas colonizarem o solo (ZILLER, 2000).

A Agricultura é realizada em pequenos lotes familiares, sendo o principal item de cultivo a mandioca (Manihot sp.), seguida do aipim, milho, cana-de-açúcar, batata, feijão, café, amendoim, cará e taiá. A mandioca é uma cultura que, além de apresentar boa produção em solos pobres, possui resistência a doenças e pragas, sendo as suas roças localizadas em Planícies Quaternárias, constituídas predominantemente por Areias Quartzosas. Predominam os sistemas de produção mandioca/milho 
DE FREITAS, R.R. \& BELTRAME, A.V. Mudanças no uso e cobertura...

e mandioca/feijão (HEIBER, 2003). A maioria das casas dos moradores tradicionais possui um pomar em seu entorno, onde são cultivadas espécies como laranja, melancia, limão, anogueiro, algodão, banana, ameixa e goiaba. No entorno da maioria das casas, também existe cultivo de plantas medicinais e galinheiro, sendo que a produção agrícola é prioritariamente destinada ao consumo familiar.

O Campo é representado por áreas de pastagem destinadas a alimentação de animais domésticos, principalmente bovinos, suínos e caprinos, sendo a sua presença um caráter distintivo dessa classe. A Urbanização corresponde aos locais onde se encontram residências, praças, comércio ou outras edificações. As residências isoladas não foram consideradas dentro da classe urbanização. $\mathrm{O}$ número de moradores foi estimado pela multiplicação do total de residências de ocupação permanente (1.888) em Janeiro de 2005, pela estimativa de 3,5 moradores por residência realizada por NMD (2003). A estimativa das residências de ocupação temporária se refere aos relógios que são ligados somente no verão, enquanto que a residências permanentes foram presumidas a partir dos relógios que se encontram permanentemente ligados (consumo superior a $50 \mathrm{Kw} / \mathrm{mês}$ ). A imprecisão do número de pousadas e hotéis, o compartilhamento do relógio com mais de um quarto, alem do elevado número de turistas que ocupam as casas de aluguel impossibilitam um número preciso da população flutuante do entorno da Lagoa de Ibiraquera.

\section{Resultados}

As mudanças no uso e cobertura da terra do entorno da Lagoa de Ibiraquera foram sintetizadas na Tabela I. Os dados apresentam um declínio na área utilizada para agricultura, que diminuiu cerca de $70 \%$ entre 1957 e 2008 e, de forma menos drástica, no campo, que diminuiu cerca de $24 \%$ para o mesmo período. Em contraposição houve um aumento vertiginoso nas áreas urbanizadas. Praticamente inexistentes em 1978, as áreas 
DE FREITAS, R.R. \& BELTRAME, A.V. Mudanças no uso e cobertura... urbanizadas passam a ocupar $15,7 \%$ do entorno da Lagoa de Ibiraquera em 2001 e 18,2\% em 2008. A vegetação nativa foi pouco alterada entre 1957 e 2008, porém há evidentes falhas nas manchas possivelmente associadas ao extrativismo vegetal seletivo.

Tabela I: Mudanças no uso da terra no entorno da Lagoa de Ibiraquera em $\mathrm{Km}^{2}$ e porcentagem (entre parêntesis) nos anos de 1957, 1978, 2001 e 2008.

\begin{tabular}{|l|c|c|c|c|c|}
\hline \multicolumn{1}{|c|}{ Classes } & CVO $^{\mathbf{a}}$ & $\mathbf{1 9 5 7}$ & $\mathbf{1 9 7 8}$ & $\mathbf{2 0 0 1}$ & \multicolumn{1}{c|}{$\mathbf{2 0 0 8}$} \\
\hline VR $^{\mathrm{b}}$ Herbácea & $1,04(2,8)$ & $1,04(2,7)$ & $1,89(5,1)$ & $2,13(5,8)$ & $1,48(4,0)$ \\
\hline VR Arbustiva & $1,72(4,7)$ & $2,72(7,3)$ & $1,96(5,3)$ & $2,3(6,2)$ & $2,35(6,4)$ \\
\hline VR Arbórea & $8,63(23,3)$ & $3,06(8,2)$ & $2,56(6,9)$ & $1,96(5,3)$ & $2,5(6,8)$ \\
\hline FOD ${ }^{\mathrm{c}}$ Submontana & $1,41(3,8)$ & $0,73(2,0)$ & $0,99(2,7)$ & $1,04(2,8)$ & $1,0(2,7)$ \\
\hline FOD de Terras Baixas & $20,07(54,3)$ & $4,58(12,3)$ & $3,78(10,4)$ & $3,9(10,6)$ & $4,47(12,2)$ \\
\hline Banhado & $0,14(0,3)$ & $0,43(1,7)$ & $0,56(1,5)$ & $0,51(1,4)$ & $0,52(1,4)$ \\
\hline Capoeirinha & - & $2,67(7,0)$ & $6,09(16,6)$ & $3,34(9,0)$ & $3,66(9,9)$ \\
\hline Campo & $0,01(0,02)$ & $8,12(22,0)$ & $9,03(24,6)$ & $7,49(20,3)$ & $6,23(16,9)$ \\
\hline Agricultura & - & $9,75(26,2)$ & $5,77(15,7)$ & $3,25(8,8)$ & $2,97(8,1)$ \\
\hline Dunas e praias & $3,95(10,7)$ & $3,95(10,6)$ & $3,83(10,5)$ & $3,82(10,4)$ & $3,8(10,3)$ \\
\hline $\begin{array}{l}\text { Urbanização Baixa } \\
\text { Densidade }\end{array}$ & - & - & $0,25(0,7)$ & $2,09(5,7)$ & $0,98(2,7)$ \\
\hline $\begin{array}{l}\text { Urbanização } \\
\text { Densidade Média }\end{array}$ & - & - & - & $1,73(4,7)$ & $5,27(14,4)$ \\
\hline $\begin{array}{l}\text { Urbanização Alta } \\
\text { Densidade }\end{array}$ & - & - & - & $1,96(5,3)$ & $0,39(1,1)$ \\
\hline Reflorestamento & - & - & - & $1,19(3,2)$ & $1,15(3,1)$ \\
\hline
\end{tabular}

${ }^{a}$ Cobertura Vegetal Original.

${ }^{\mathrm{b}}$ Vegetação de Restinga.

${ }^{\mathrm{c}}$ Floresta Ombrófila Densa

Com base na organização espacial do entorno da Lagoa de Ibiraquera, os resultados das mudanças no uso e cobertura da terra foram divididos em duas fases, isolamento espacial e exploração turística. A primeira fase corresponde à chegada dos imigrantes açorianos no entorno da Lagoa de Ibiraquera, por volta de 1880 até a década de 1970 do século XX. A análise da organização espacial 
DE FREITAS, R.R. \& BELTRAME, A.V. Mudanças no uso e cobertura...

da área de estudo nesse período é realizada com base em dados sobre a Cobertura Vegetal Original até 1957 ( $1^{\circ}$ Período) e nos mapas de uso e cobertura da terra de 1957 até 1978 (2ºríodo). A segunda fase corresponde ao final da década de 1970 até 2008, sendo a análise da organização espacial realizada a partir dos mapas de uso e cobertura da terra de 1978 até 2001 (3ºríodo) e de 2001 até 2008 ( $4^{\mathrm{a}}$ Período).

\section{Fase de isolamento espacial}

A Fase de Isolamento Espacial foi caracterizada pela ausência de redes viárias integrando o entorno da Lagoa de Ibiraquera com o território nacional. O $1^{\circ}$ Período (1880 a 1957) é antecedido pela ocupação humana do litoral catarinense iniciada pelos índios Carijós há cerca de 5.000 anos (SANTOS, 1977). Para evitar o domínio espanhol, no século XVIII Portugal incentivou a migração de açorianos e madeirenses para a zona costeira do Sul do Brasil (PELUSO Jr., 1991 e SANTOS, 1977). A colonização da zona costeira foi caracterizada pelo minifúndio e pela policultura de subsistência, sendo a escravidão essencialmente doméstica (PEREIRA, 2003 e SANTOS, 1977). O município de Imbituba iniciou como núcleo de colonização açoriana e bandeirante em 1715 e o entorno da Lagoa de Ibiraquera recebeu suas primeiras levas de ocupantes em 1880 (AVELLAR, 1993). A pescaria constituía a principal atividade econômica em função das demandas internas e externas por óleo de baleia. Até a década de 1960, as famílias asseguravam sua subsistência mediante a combinação de atividades agrícolas, em especial no plantio da mandioca, com comercialização do excedente da farinha, pesca e caça (SEIXAS, 2002).

As comunidades mais antigas do entorno da Lagoa de Ibiraquera são Araçatuba, Arroio, Ibiraquera e Campo D'uma, sendo as demais formadas na década de 1980 do século XX. Em 1957, há preponderância da agricultura, a qual era basicamente formada por roças de mandioca (Figura 02). Segundo PIAZZA 
DE FREITAS, R.R. \& BELTRAME, A.V. Mudanças no uso e cobertura...

(1956), desde os primeiros anos de seu povoamento, Santa Catarina foi um centro produtor da mandioca e exportador da sua farinha. Em 1957, 48,2\% do entorno da Lagoa de Ibiraquera correspondiam a Agricultura (26,2\%) e Campo (22\%). Em relação à Cobertura Vegetal Original em 1957: (i) as áreas de Floresta Ombrófila Densa Submontana e de Terras Baixas diminuíram $51,7 \%$ e $77,2 \%$, respectivamente, enquanto que a Vegetação de Banhado aumentou em 1,7\%; (ii) a Vegetação de Restinga Arbórea diminuiu 64,5\%; (iii) a Floresta Ombrófila Densa de Terras Baixas do entorno da Lagoa Doce do Arroio possuía uma área cinco vezes maior; (iv) a Vegetação de Restinga Arbustiva se apresenta bem conservada.

O "Mato Queimado", maior fragmento de Vegetação de Restinga Arbórea do entorno da Lagoa de Ibiraquera $\left(5,69 \mathrm{Km}^{2}\right)$, estava conectado com fragmentos maiores, principalmente a noroeste em 1957. Este fragmento abrangia as Praias do Ouvidor, Vermelha e Rosa até o morro do Elegante, além das manchas localizadas na beira da Lagoa de Cima na comunidade de Ibiraquera e Grama. O "Lagamar", maior fragmento de Floresta Ombrófila Densa de Terras Baixas $\left(0,54 \mathrm{Km}^{2}\right)$, também estava conectado com fragmentos maiores. Em 1957, os três fragmentos de Floresta Ombrófila Densa de Terras Baixas próximos da Lagoa Doce do Arroio formavam um contínuo com a vegetação da Barra $\left(1,81 \mathrm{Km}^{2}\right)$, havendo poucos fragmentos florestais ao sul e a oeste.

O $2^{\circ}$ Período da Fase de Isolamento Espacial foi marcado pela construção da Rodovia BR 101, diminuição nas atividades agrícolas e na vegetação nativa (Figura 03). Construída na década de 1970, a Rodovia BR 101 criou um divisor de águas no limite oeste, formando uma Microbacia Hidrográfica no entorno da Lagoa de Ibiraquera. Em 1978 diminuíram as Vegetações de Restinga Arbustiva (27,8\%) e Arbórea (16,3\%), bem como a Floresta Ombrófila Densa de Terras Baixas (17,1\%). A extração da Vegetação de Restinga da Barra gerou uma descontinuidade com a Floresta Ombrófila Densa de Terras Baixas do Arroio. 
DE FREITAS, R.R. \& BELTRAME, A.V. Mudanças no uso e cobertura...

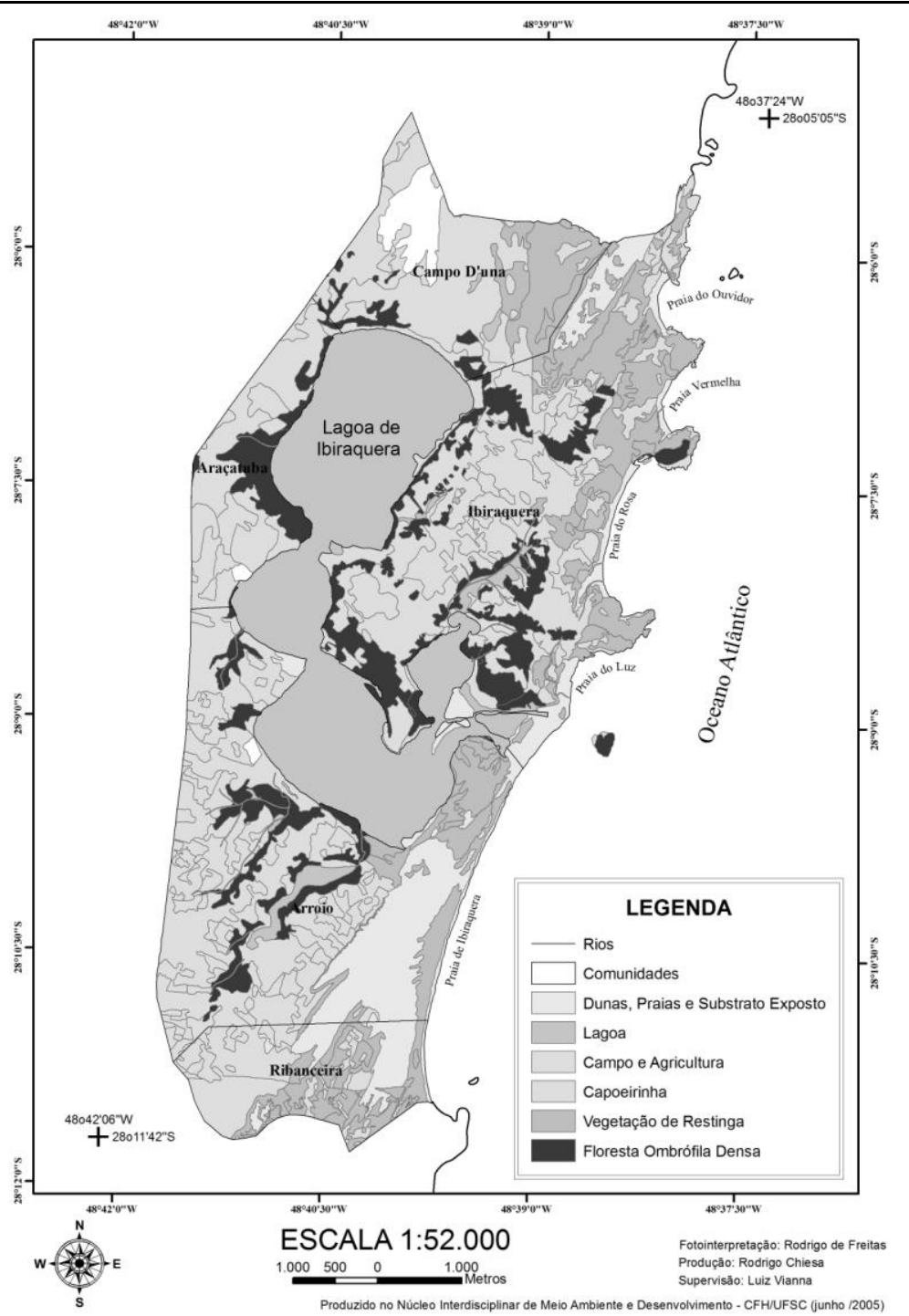

FIGURA 02: Mapa de uso e cobertura da terra de 1957 do entorno da Lagoa de Ibiraquera, Santa Catarina (Brasil). 
DE FREITAS, R.R. \& BELTRAME, A.V. Mudanças no uso e cobertura...

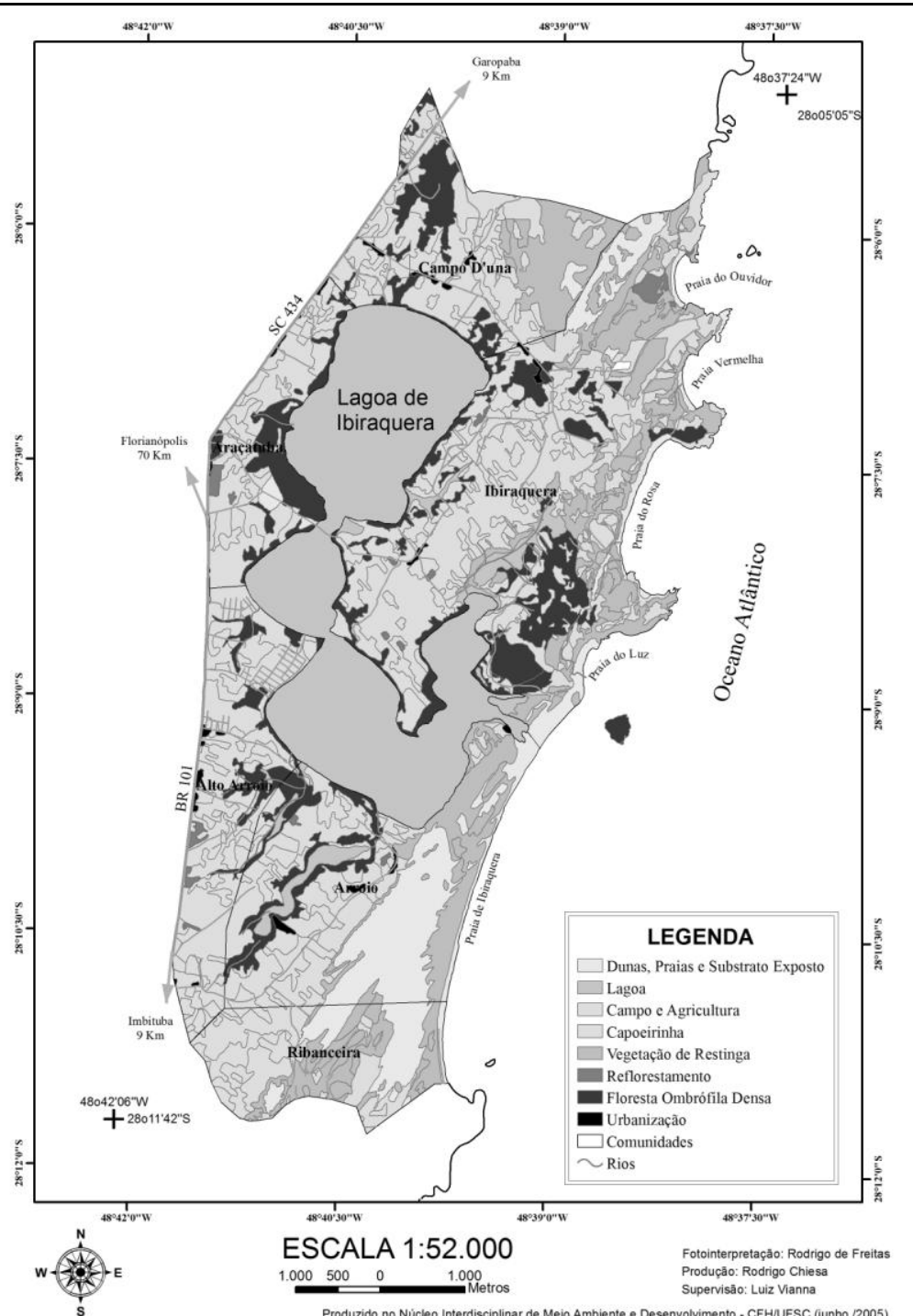

FIGURA 03: Mapa de uso e cobertura da terra de 1978 do entorno da Lagoa de Ibiraquera, Santa Catarina (Brasil). 
DE FREITAS, R.R. \& BELTRAME, A.V. Mudanças no uso e cobertura...

As áreas de cultivos (Agricultura) diminuíram 40,8\%, gerando um aumento de $136,8 \%$ nas áreas de Capoeirinha, principalmente nas comunidades de Ibiraquera, Campo D'una, Limpa e Araçatuba. O abandono da Capoeirinha do Morro do Elegante para atividades agrícolas gerou um aumento 35,2\% em uma Floresta Secundária classificada como Floresta Ombrófila Densa Submontana. O Campo expandiu $11,2 \%$, possivelmente sobre áreas queimadas, tendo em vista a facilidade que as gramíneas colonizam esse tipo de ambiente.

\section{Fase de exploração turística}

A construção da Rodovia BR 101 no final da década de 1970 aumentou o acesso de visitantes ao entorno da Lagoa de Ibiraquera. Mesmo que em velocidades diferentes, todas as comunidades experimentam um declínio nas atividades econômicas tradicionais (pesca artesanal e agricultura familiar). O turismo e a construção de residências secundárias passam a imprimir um ritmo para a paisagem, relacionado à recepção de migrações humanas massivas durante o verão. A principal característica da organização espacial da fase de exploração turística foi o aumento da área com Urbanização.

No final dos anos 1970, o entorno da Lagoa de Ibiraquera passou a se beneficiar com os incentivos governamentais para obter madeira visando atender a construção civil. O resultado desta ação foi que, em 2001, as áreas de reflorestamento com espécies exóticas passaram a representar $3,2 \%$ da área total. O plantio dos gêneros Pinus e Casuarina em área de Dunas vêm sendo utilizado como forma de descaracterizar a vegetação de Restinga, visando obter as licenças ambientais necessárias à construção residenciais.

Estima-se que entre 1957 e 2001, a população do entorno da Lagoa de Ibiraquera tenha passado de 900 para 6.608 moradores. Entre 1996 e 2000, a população total de Imbituba cresceu $12 \%$ e a de Garopaba $11 \%$ (IBGE, 2012), enquanto que a PLI registrou um crescimento populacional de 8,32\% entre 2000 e 2005 (Tabela II). $\mathrm{O}$ fato das residências de ocupação sazonal corresponderem a quase dois terços do total de residências, faz com que a população 
DE FREITAS, R.R. \& BELTRAME, A.V. Mudanças no uso e cobertura...

do entorno da Lagoa de Ibiraquera aumente em pelo menos três vezes durante a temporada de verão.

TABELA II: Estimativa do total de residências das comunidades do entorno da Lagoa de Ibiraquera e do crescimento médio anual (2000 a 2005). As porcentagens estão em itálico entre parêntesis e os totais referem-se às médias (Fonte: CERPALO ${ }^{2}$ CELESC $^{3}$; NMD, 2003).

\begin{tabular}{|l|c|c|c|c|}
\hline Comunidades & $\begin{array}{c}\text { Ocupação } \\
\text { Permanente }\end{array}$ & $\begin{array}{c}\text { Ocupação } \\
\text { sazonal }\end{array}$ & $\begin{array}{c}\mathbf{N} \\
\text { residência } \\
\text { S }\end{array}$ & $\begin{array}{c}\text { TCA } \\
*(\%)\end{array}$ \\
\hline Alto Arroio & $52(20,8)$ & $198(79,2)$ & 250 & 4,15 \\
\hline Araçatuba & $158(45,66)$ & $188(54,34)$ & 346 & 6,95 \\
\hline Arroio & $138(43,40)$ & $180(56,60)$ & 318 & 6,24 \\
\hline Barra & $119(25,70)$ & $344(74,30)$ & 463 & 11,86 \\
\hline Ibiraquera & $398(36,69)$ & $676(63,31)$ & 1074 & 10,87 \\
\hline Rosa & $333(44,82)$ & $410(55,18)$ & 743 & 9,83 \\
\hline $\begin{array}{l}\text { Campo D'una, } \\
\text { Limpa e Grama }\end{array}$ & $690(46)$ & $810(54)$ & 1500 & 8,32 \\
\hline Total & 1888 & 2806 & 4694 & 8,32 \\
\hline
\end{tabular}

*Taxa de Crescimento Anual

A Urbanização passa a ser expressiva a partir do mapa de 2001, quando ocupava 15,6\% do entorno da Lagoa de Ibiraquera (Figura 04). Entre os anos de 2001 e 2008, o aumento da urbanização em todo o entorno da Lagoa de Ibiraquera, principalmente sobre áreas de Floresta Ombrófila Densa de Terras Baixas, levou a diminuição na área ocupada pela Vegetação de Banhado, que foi drenado para as construções. De 2001 para 2008 as áreas urbanizadas aumentaram em mais de 15\%, correspondendo a um crescimento de 2,2\% ao ano (Figura 05).

${ }^{2}$ Cooperativa de Eletrificação Rural de Paulo Lopes que abastece as comunidades pertencentes ao município de Imbituba: Barra, Arroio, Alto Arroio, Ibiraquera e Araçatuba. A Ribanceira não foi analisada.

${ }^{3}$ Centrais Elétricas de Santa Catarina S.A. 
DE FREITAS, R.R. \& BELTRAME, A.V. Mudanças no uso e cobertura...

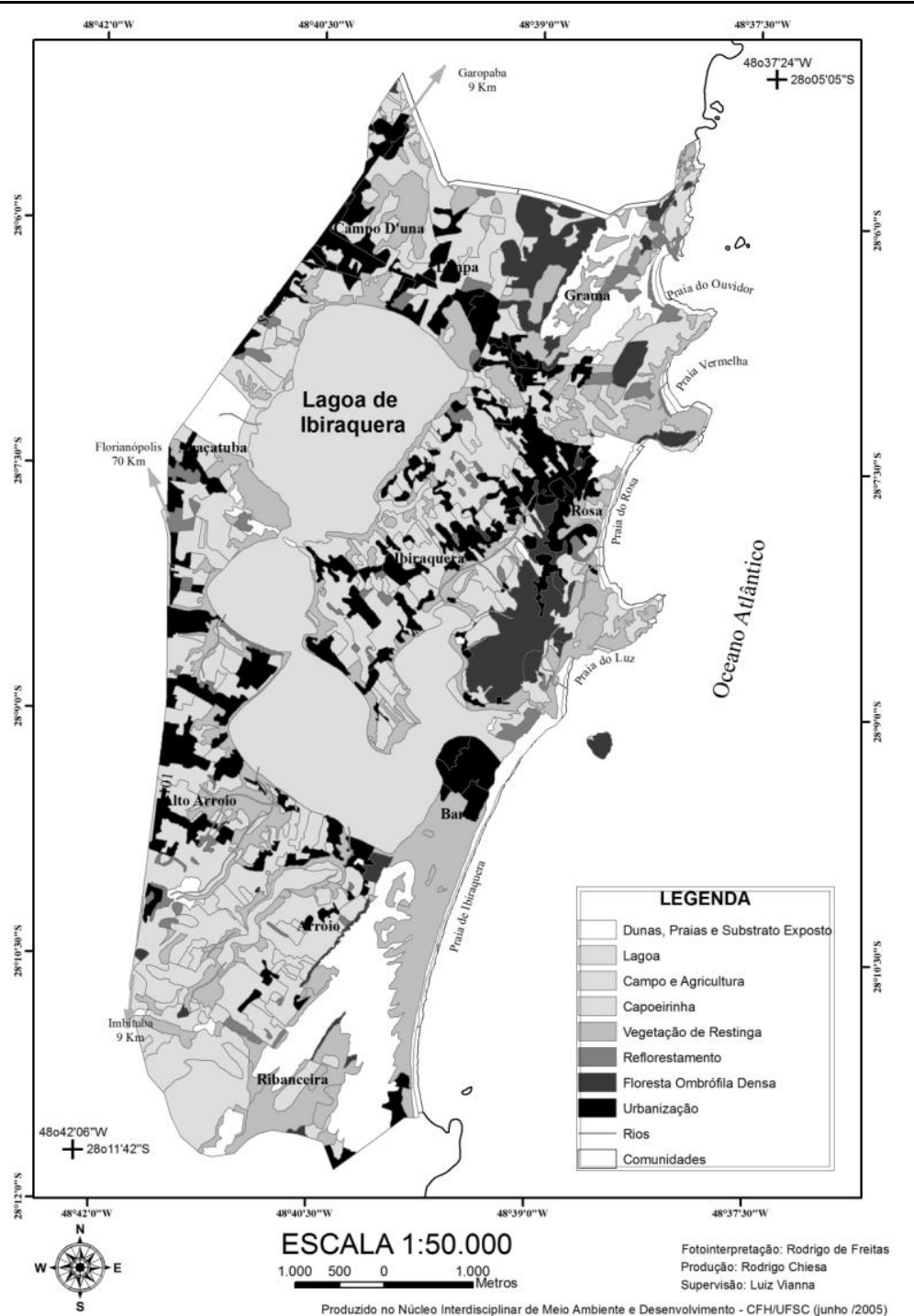

FIGURA 04: Mapa de uso e cobertura da terra de 2001 do entorno da Lagoa de Ibiraquera, Santa Catarina (Brasil). 
DE FREITAS, R.R. \& BELTRAME, A.V. Mudanças no uso e cobertura...

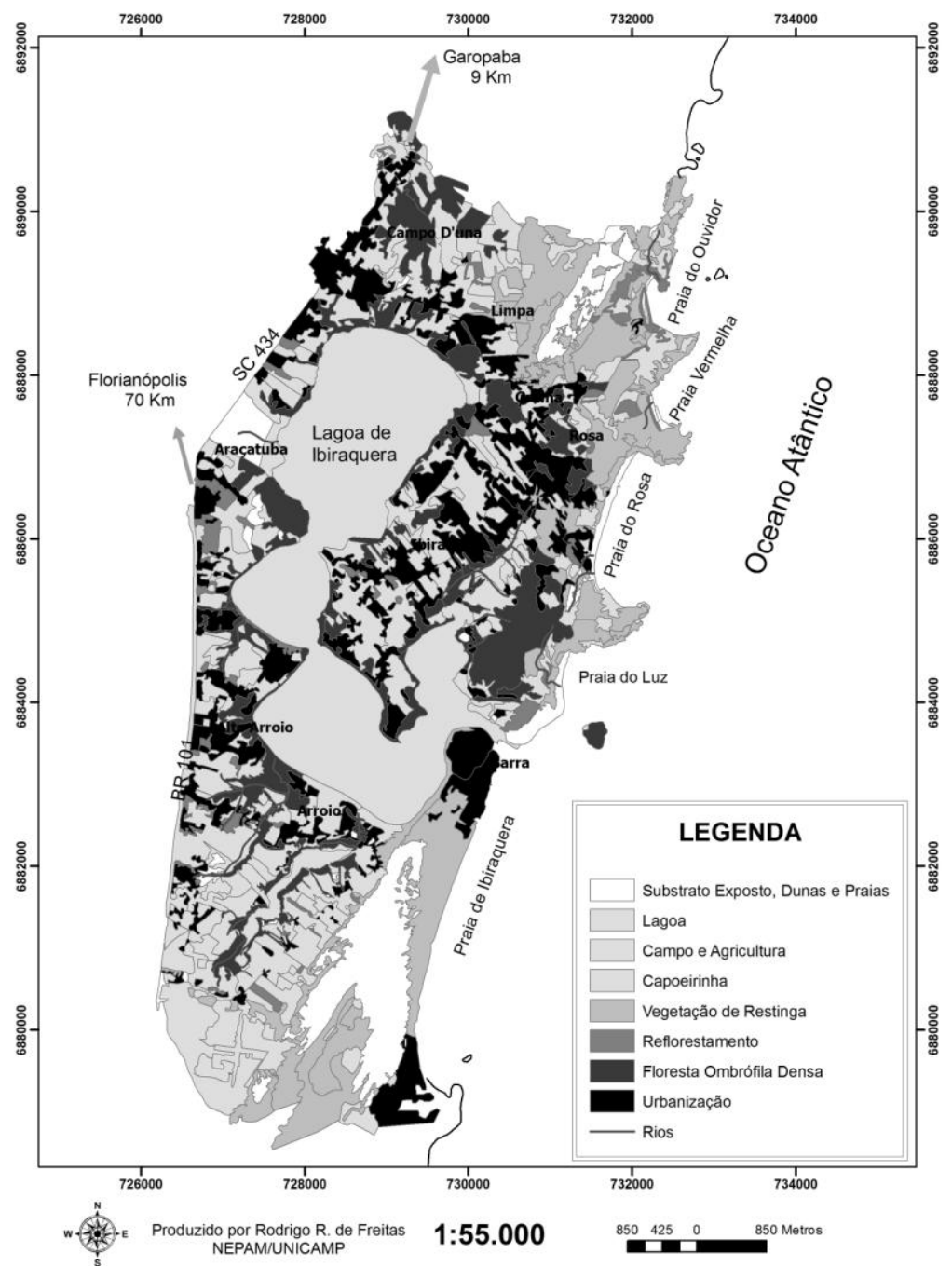

FIGURA 05: Mapa de uso e cobertura da terra de 2008 do entorno da Lagoa de Ibiraquera, Santa Catarina (Brasil). 
DE FREITAS, R.R. \& BELTRAME, A.V. Mudanças no uso e cobertura...

A partir de 2008, iniciaram as obras de duplicação da Rodovia BR 101, cujos feitos são perceptíveis espacialmente pela ocupação humana, na forma de residências, nos espaços mais afastados do mar e da Lagoa. Em função desta ocupação, houve retração da Floresta Ombrófila Densa de Terras Baixas no Arroio.

\section{Discussão}

A diminuição dos terrenos agrícolas e do campo e a manutenção ou aumento da vegetação nativa, bem como o crescimento urbano exponencial, representam um padrão encontrado em outras regiões costeiras do mundo (THOMLINSON, 1996; RUIZ-LUNA e BERLANGA-ROBLES, 2003; SHI E SINGH, 2003; FALCUCCI et al., 2007). Em Santa Catarina, a principal causa do desmatamento das Vegetações de Restinga está relacionada à expansão urbana na forma de loteamentos isolados próximo às praias (FUNDAÇÃO S.O.S. MATA ATÂNTICA \& INPE, 1993).

As três hipóteses levantadas por DOMON e BOUCHAR (2007) sobre mudança na paisagem e ampliadas por BÜRGI et al. (2010) são corroboradas por este estudo de caso, com algumas considerações:

\section{Mudanças na paisagem permanecem fortemente associadas} às características geomorfológicas dos territórios: Esta hipótese passa a fazer sentido para o entorno da Lagoa de Ibiraquera caso as características do relevo estejam associadas à formação dos solos. As primeiras ocupações humanas no entorno da Lagoa de Ibiraquera ocorreram nas Florestas Ombrófilas Densas de Terras Baixas. Esta classe de cobertura da terra está situada nas depressões abaixo de $30 \mathrm{~m}$, formando solos mais propensos à agricultura. Por outro lado, as dunas e a Vegetação de Restinga foram conservadas por não serem ambientes adequados para $o$ desenvolvimento de atividades agrícolas. 
DE FREITAS, R.R. \& BELTRAME, A.V. Mudanças no uso e cobertura...

II. Mudanças na paisagem representam uma extensão das demandas socioeconômicas para bens e serviços ecossistêmicos: Até o final da década de 1970, o espaço do entorno da Lagoa de Ibiraquera era estruturado pela manutenção do modo de vida tradicional, assentados na pesca e na agricultura. $\mathrm{O} 2^{\circ}$ Período da Fase de Isolamento Espacial (1957 a 1978) foi marcado pelos efeitos das emigrações para centros urbanos. As emigrações do entorno da Lagoa de Ibiraquera estiveram associados ao esgotamento dos recursos naturais. Entrevistados relataram um empobrecimento dos recursos madeireiros e dos solos devido à prática da coivara e a falta de terra nova devido a fragmentação das propriedades por herança a numerosos filhos (CAMPOS, 1991).

A lenha utilizada em fogões e fornos para produção da farinha de mandioca passou a ser adquirida em locais mais distantes e a demanda por madeiras para construção passou a ser atendida pelas espécies exóticas que foram introduzidas. Em Araçatuba, a principal causa de desmatamento esteve associada à extração de lenha, seguido da queimada e do cultivo de arroz. Além disso, entre 1970 e 1981 a Lagoa de Ibiraquera passou por uma crise na pescaria (SEIXAS, 2002). Após a construção da Rodovia BR 101 há uma apropriação generalizada dos terrenos no entorno da Lagoa de Ibiraquera por moradores de fora atraídos pelo turismo que é mantido pela conservação da vegetação nativa. Assim, as mudanças na paisagem foram geradas por demandas socioeconômicas cujos efeitos são evidenciados na organização espacial da paisagem.

III. A tecnologia determina como a demanda para certos bens e serviços são traduzidos para o uso da terra. Novas tecnologias devem ser acessíveis, socialmente aceitas e corresponder à demanda para ser amplamente aplicada e para causar uma transformação tecnológica e consequente transformação na paisagem: Esta hipótese não pode estar descolada do contexto político em que as técnicas foram utilizadas. Algumas tecnologias desempenharam um papel chave para oferecer respostas à escassez de recursos naturais locais na mudança da paisagem. A falta de lenha, por exemplo, foi solucionada pela 
DE FREITAS, R.R. \& BELTRAME, A.V. Mudanças no uso e cobertura...

popularização dos fogões a gás na década de 1980. A prática das queimadas, frequente no passado, tem sido abandonada em função da adoção do arado (HEIBER, 2003). Gradualmente, o turismo e o comércio, inclusive de pescado, começaram a ocupar cada vez mais espaço na renda da população local e a agricultura passou a ser exercida como atividade parcial de subsistência. O perfil de desenvolvimento da década de 1980, período conhecido como "milagre brasileiro" foi fortemente marcado pela chegada de tecnologias no entorno da Lagoa de Ibiraquera (SEIXAS, 2002), a partir das seguintes mudanças: (a) construção do principal acesso rodoviário (BR 101); (b) instalação da rede de energia elétrica (viabilizando a opção de conservação do pescado) e; (c) expansão do comércio local.

$\mathrm{Na}$ fase de exploração turística, a valorização da paisagem marítima passou a fomentar novas migrações para locais próximos ao mar e à lagoa. A rede viária (BR 101) possibilitou a integração do entorno da Lagoa de Ibiraquera ao mercado regional e nacional (PEREIRA, 2003), trazendo novas tecnologias às comunidades. As redes viária e elétrica geraram maior fluxo de pessoas e mercadorias e o consequente aumento na área urbanizada. $\mathrm{Na}$ década de 90, muitos moradores nativos que haviam migrado para outras regiões do Estado ou do País anteriormente retornam trazendo consigo suas economias e novas agendas de desenvolvimento (SEIXAS, 2002).

As implicações e os desafios em termos de conservação e desenvolvimento associados a este padrão de uso da terra estão relacionados à conectividade entre as manchas de vegetação nativa e ao tratamento da poluição gerada pela urbanização. $O$ aumento na conectividade nas manchas deve ser parte de uma estratégia territorial de desenvolvimento, que considere a integração da paisagem analisada com a região onde ela está inserida. A expansão urbana desordenada sobre ambientes frágeis, tem contribuído para a contaminação de estuários e aquíferos, podendo ocasionar a eutrofização destes ambientes (RUIZLUNA e BERLANGA-ROBLES, 2003). Neste caso, uma nova crise na paisagem pode ser gerada pela baixa qualidade de vida, falta de interesse turístico e pela degradação dos recursos pesqueiros. 
DE FREITAS, R.R. \& BELTRAME, A.V. Mudanças no uso e cobertura...

\section{Considerações finais}

O histórico das mudanças no uso e cobertura da terra da paisagem do entorno da Lagoa de Ibiraquera evidencia padrões que auxiliam na construção de hipóteses visando sustentar uma teoria das mudanças na paisagem. A urbanização foi a principal tendência observada no entorno da Lagoa de Ibiraquera. Algumas características associadas à urbanização são o aumento do valor da terra e a falta de áreas para restauração de ecossistemas. O caso do entorno da Lagoa de Ibiraquera demonstra a importância em conservar os fragmentos de vegetação nativa enquanto matrizes para a regeneração da vegetação em níveis mais amplos da escala espacial. Desta forma, os resultados deste estudo podem ser utilizados no planejamento de ações integradas de desenvolvimento e conservação do complexo de lagoas costeiras existentes no litoral gaúcho e centro-sul de Santa Catarina.

\section{Agradecimentos}

Agradecemos ao Prof. Dr. Paulo Freire Vieira (NMD/UFSC) pelo suporte de campo; ao Eng. Rodrigo Chiesa pela assessoria na confecção dos mapas; à Empresa de consultoria AeroConsult pelas fotos aéreas; a Universidade do Vale do Itajaí (UNIVALI) pela licença para uso do SIG; a Pós-Graduação em Geografia da UFSC e ao Conselho Nacional de Desenvolvimento Científico e Tecnológico $(\mathrm{CNPq})$ pelo suporte financeiro. Estendemos nosso agradecimento aos comentários valorosos de um referee anônimo.

\section{Referências bibliográficas}

AVELLAR, M.L. 1993. Ibiraquera: historia de um lugar... um movimento singular e universal. Dissertação de Mestrado. Centro de Educação (CED). Universidade Federal de Santa Catarina (UFSC). 187p. 
DE FREITAS, R.R. \& BELTRAME, A.V. Mudanças no uso e cobertura...

BECHARA, F.C. 2003. Restauração ecológica de restingas contaminadas por Pinus no Parque Florestal do Rio Vermelho, Florianópolis, SC. Dissertação de Mestrado. Biologia Vegetal. Universidade Federal de Santa Catarina. 125p.

BÜRGI, M.; STRAUB, A.; GIMMI, U.; SALZMANN, D. 2010. A recente história da paisagem de Limpach valley, Switzerland: considerando três hipóteses empíricas sobre forças direcionadoras das mudanças na paisagem. Landscape Ecol. 25:287-297.

CARUSO, M.M.L. 1983. O desmatamento da Ilha de Santa Catarina de 1500 aos dias atuais. Florianópolis, Editora da UFSC.

DOMON, G.; BOUCHARD A. 2007. The landscape history of Godmanchester (Quebec, Canada): two centuries of shifting relationships between anthropic and biophysical factors. Landscape Ecol. 22: 1201-1214

FALCUCCI, A.; MAIORANO, L.; BOITANI, L. 2007. Changes in land-use/land-cover patterns in Italy and their implications for biodiversity conservation. Landscape Ecol. 22:617-631.

FREITAS, R.R. e BELTRAME, A.V. 2011. Biogeografia e Cobertura Vegetal Original da Paisagem da Lagoa de Ibiraquera (Santa Catarina, Brasil) Submetido. Rev. T. Livre.

FUNDAÇÃO S.O.S. MATA ATLÂNTICA \& INPE.1993. Atlas da evolução dos remanescentes florestais e ecossistemas associados ao domínio da Mata Atlântica no Estado de Santa Catarina no período de 1985 e 1990. São Paulo 23p.

HEIBER, C.E. 2003. Avaliação Sócio-ambiental da agricultura na Região da Lagoa de Ibiraquera, nos municípios de Imbituba e Garopaba - SC. Seminário de Iniciação Científica PIBIC UFSC. Florianópolis (SC).

IBGE, 2012. Site oficial: http://www.ibge.gov.br/home/. Acessado em 08/06/12. 
DE FREITAS, R.R. \& BELTRAME, A.V. Mudanças no uso e cobertura...

NMD, 2003. Núcleo Interdisciplinar de Meio Ambiente e Desenvolvimento, Universidade Federal de Santa Catarina (UFSC). Relatório Interno.

PEREIRA, R.M.F.A., 2003. Formação sócio-espacial do litoral de Santa Catarina (Brasil): gênese e transformações recentes. Geosul, Florianópolis, 18 (35): 99-129.

RUIZ-LUNA, A.; BERLANGA-ROBLES, C.A. 2003. Land use, land cover changes and coastal lagoon surface reduction associated with urban growth in northwest Mexico. Landscape Ecology 18: 159-171.

SEIXAS, 2002. Social-Ecological Dynamics in Management Systems: investigating a coastal lagoon fishery in Southern Brazil. Ph.D. in Natural Resources and Environmental Management. University of Manitoba - Canada. 265p.

SHI, H.; SINGH, A. 2003. Status e interconexões de Questões Ambientais Selecionadas nas Zonas Costeiras Globais. Ambio 32(2): 145-152.

THOMLINSON, J.R.; SERRANO, M.I.; LOPEZ, T.M.; AIDE, T.M.; ZIMMERMAN, J.K. 1996. Land-Use Dynamics in a PostAgricultural Puerto Rican Landscape (1936-1988). Biotropica 28(4) Special Issue: 525-536.

THOMPSON, P. 1992. A voz do Passado: História Oral. Editora Paz e Terra S.A. 385p.

ZILLER, S.R. 2000. A estepe gramíneo-lenhosa no segundo planalto do Paraná: diagnóstico ambiental com enfoque à contaminação biológica. Tese de doutorado. Universidade Federal do Paraná, Brasil, 268pp. 